\title{
Atypical Presentation of a Pigmented Oncocytoma of the Caruncle: A Case Report
}

\author{
Maura Di Nicola ${ }^{a}$ Elisabetta Miserocchi ${ }^{a} \quad$ Nathalie Rizzo ${ }^{b}$ \\ Charlene L. Grantoza $^{a} \quad$ Francesco Bandello $^{a}$ Giulio Modorati ${ }^{a}$ \\ Departments of ${ }^{a}$ Ophthalmology and ${ }^{b}$ Pathology, Scientific Institute San Raffaele, \\ Vita-Salute University, Milan, Italy
}

\section{Key Words}

Oncocytoma $\cdot$ Nevus $\cdot$ Conjunctival neoplasm

\begin{abstract}
We report an unusual case of a pigmented oncocytoma of the caruncle. The lesion presented the following atypical features: a well-circumscribed, partially pigmented, and lobulated mass that macroscopically resembled a caruncular nevus. However, an excision biopsy revealed an oncocytoma instead. Thus, although nevi are the most common lesions found in the caruncle, oncocytoma should also be considered in the differential diagnosis of a pigmented caruncular mass, especially in elderly female patients.
\end{abstract}

\section{Introduction}

Oncocytes are defined as modified epithelial cells with characteristic finely granular eosinophilic cytoplasm, which are abundant in mitochondria [1-4]. Oncocytic cells are also known as Hürthle, Askanazy, and oxyphil cells [5]. Tumors composed of oncocytes have been described in the major and minor salivary glands, the thyroid, parathyroid, pituitary, and adrenal glands as well as in the kidneys, testes, pharynx, larynx, trachea, pancreas, respiratory tract, skin, and other organs $[1,5]$.

In the vast majority of cases [3], oncocytic lesions of the ocular adnexa occur in the caruncle; other locations rarely include the conjunctiva, plica semilunaris, lacrimal sac, eyelid, and lacrimal gland $[1,4,6]$. Oncocytic lesions occur more commonly in elderly patients, usually in their seventh decade of life, with a 2:1 female:male ratio, especially for those occurring in the caruncle $[1,5,6]$. The most common presenting symptom is a mass or

Maura Di Nicola, MD

Department of Ophthalmology, Scientific Institute San Raffaele

Vita-Salute University, Via Olgettina 60

IT-20132 Milan (Italy)

E-Mail m.dinicola@studenti.unisr.it 
lump, although patients are usually asymptomatic [4,5]. Oncocytic lesions of the eye are generally benign [3], and complete surgical excision is the preferred treatment since it has often proved to be curative [4].

\section{Case Presentation}

A 69-year-old woman was referred to the Ocular Oncology Service for the evaluation of a pigmented mass in the caruncular region of the right eye. The patient was regularly followed for chronic blepharoconjunctivitis in both eyes and dry eye syndrome, treated with lubricant eye drops. There was no history of eye surgery or trauma. The patient took daily medications for hypertension and was suspected to have rosacea. Aside from this, her personal medical history and family history were unremarkable.

The patient complained of a tan-colored lesion on her right caruncle, but denied symptoms of bleeding, discharge, an increase in size, or a color change of the lesion. On ocular examination, visual acuity was $20 / 20$ and intraocular pressure was $16 \mathrm{~mm} \mathrm{Hg}$ in both eyes. Slit lamp biomicroscopy revealed a well-circumscribed, partially pigmented lesion in the caruncle of the right eye. The lesion had a slightly lobulated surface with visible superficial vessels (fig. 1a). No involvement of the lacrimal system was noted, and the dilated fundus examination of both eyes was unremarkable. The patient was diagnosed with conjunctival nevus of the right caruncle.

Due to the lesion's unfavorable location, the patient was advised to undergo complete surgical excision of the caruncular mass. The excised specimen was submitted for histopathological evaluation.

Histopathological examination disclosed a benign, cystic, tubular, well-circumscribed lesion composed of tall, columnar, granular eosinophilic cells (fig. 1b). A thin fibrous tissue capsule penetrating the tumor from the periphery was also present. The pigmented macroscopic appearance of the lesion was thought to be due to concretions within the tumor (fig. 1b).

A diagnosis of oncocytoma of the caruncle was made.

\section{Discussion}

An oncocytoma is a rare benign tumor that usually arises in the glandular epithelia of tissues throughout the body [7]. Among cutaneous sites, the ocular caruncle is the most common presenting site $[1,3]$. Oncocytomas have also been known as oxyphil adenomas, papillary cystadenomas, adenolymphoma-like tumors, and Warthin's tumor [2]. The lesion is usually composed of large oval cells with eosinophilic granular cytoplasm filled with malformed mitochondria, most likely representing an age-associated metaplastic and neoplastic transformation of the glandular epithelium [8]. Clinically, caruncular oncocytomas occur more frequently in female elderly patients $[1,4,6]$ and usually present as a mass or lump that rarely shows a tendency to grow [4]. They are commonly red-blue or orangetan in color, sometimes with a lobulated, fleshy, or cystic appearance [6].

Histopathologically, oncocytomas have been attributed with four main architectural patterns: cystic-micropapillary, confluent-glandular, solid-organized, and solid-disorganized [5]. Benign lesions are commonly described as having a cystic-micropapillary pattern, while potentially aggressive growth is associated with solid patterns [5]. 
Di Nicola et al.: Atypical Presentation of a Pigmented Oncocytoma of the Caruncle: A Case Report

Reported atypical features of oncocytomas include the presence of pigmentation, feeder vessels, keratinization, a pedunculated growth pattern, and superficial lobulations [4]. Furthermore, it has been reported that oncocytomas that are not dark blue in color are more likely to be misdiagnosed preoperatively [4]. Surgical treatment outcomes are excellent for benign oncocytic neoplasms, with no recurrence found after surgical excision $[1,4]$.

Several entities must be taken into consideration in the differential diagnosis of caruncular lesions. Nevi (40.7\%), squamous papillomas (8.5\%), and oncocytomas (5.1\%) are the most common lesions at this body site [6]. Other commonly reported lesions include sebaceous gland hyperplasia and pyogenic granuloma [8]. More specifically, oncocytomas are clinically often mistaken for hemangiomas, nevi, and cysts [9].

The case we reported showed several atypical characteristics: the lesion was partially pigmented and lobulated and its macroscopic appearance resembled that of a conjunctival nevus. Therefore, we decided to excise the lesion. Conjunctival nevi tend to remain stationary throughout life, with less than $1 \%$ risk for transformation into malignant melanoma [10]. Nevertheless, malignant melanoma of the conjunctiva is a potentially lifethreatening tumor. Tumors found in unfavorable locations such as the palpebral conjunctiva, fornices, plica, caruncle, and lid margins have been associated with a higher rate of metastatic death [11]. Given this knowledge, the surgical management of the lesion in our case seemed the most appropriate treatment. Pathology ultimately revealed the lesion as an oncocytoma of the caruncle. Nevertheless, complete surgical excision had already been performed, and no further treatment was required. At follow-up after 12 months, the patient remained asymptomatic, with no signs of recurrence of the oncocytoma.

In conclusion, although nevi are the most common lesions present in the caruncle, oncocytoma should be considered in the differential diagnosis of a pigmented caruncular mass, especially in elderly female patients.

\section{Disclosure Statement}

The authors have no conflicts of interest to disclose.

\section{References}

1 Biggs SL, Font RL: Oncocytic lesions of the caruncle and other ocular adnexa. Arch Ophthalmol 1977;95:474-478.

2 Rennie IG: Oncocytomas (oxyphil adenomas) of the lacrimal caruncle. Br J Ophthalmol 1980;64:935-939.

3 Orcutt JC, Matsko TH, Milam AH: Oncocytoma of the caruncle. Ophthal Plast Reconstr Surg 1992;8:300-302.

- 4 Say EAT, Shields CL, Bianciotto C, Eagle RC Jr, Shields JA: Oncocytic lesions (oncocytoma) of the ocular adnexa: report of 15 cases and review of literature. Ophthal Plast Reconstr Surg 2012;28:14-21.

5 George E, Swanson PE, Newman BK, Wick MK: Oculocutaneous oncocytic tumors: clinicopathologic and immunohistochemical study of 2 cases with literature review. Am J Dermatopathol 2007;29:279-285.

6 Kapil JP, Proia AD, Puri PK: Lesions of the lacrimal caruncle with an emphasis on oncocytoma. Am J Dermatopathol 2011;33:227-235.

7 Morgan MB, Truitt CA, Romer C, Somach S, Pitha JV: Ocular adnexal oncocytoma: a case series and clinicopathologic review of the literature. Am J Dermatopathol 1998;20:487-490.

8 Chang WJ, Nowinski TS, Eagle RC Jr: A large oncocytoma of the caruncle. Arch Ophthalmol 1995;113:382. Mohan ER, Biswas J, Krishnakumar S: Oncocytoma of the caruncle. Indian J Ophthalmol 2002;50:60-61. Shields CL, Shields JA: Tumors of the conjunctiva and cornea. Surv Ophthalmol 2004;49:3-24.

Paridaens AD, Minassian DC, McCartney AC, Hungerford JL: Prognostic factors in primary malignant melanoma of the conjunctiva: a clinicopathological study of 256 cases. Br J Ophthalmol 1994;78:252-259. 


\section{Case Reports in \\ Ophthalmology}

Case Rep Ophthalmol 2013;4:16-19

DOI: $10.1159 / 000353222$

Nicola et al: Atypical Presentation of a Pigment

Case Report
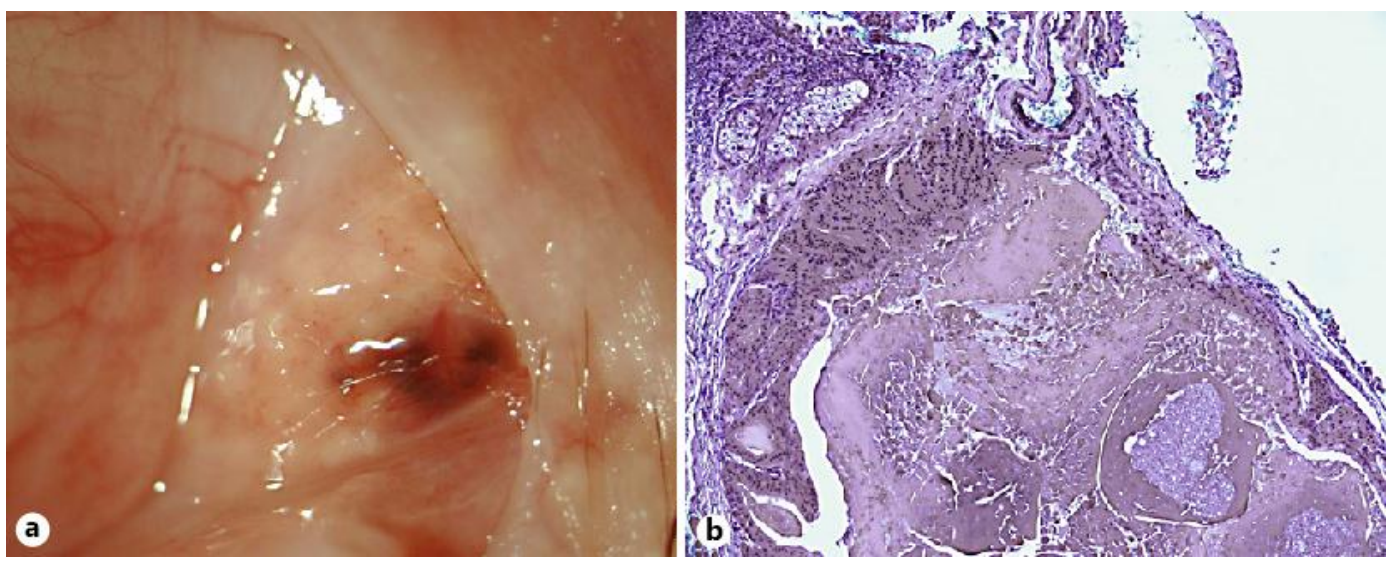

Fig. 1. a Macroscopic appearance of the caruncular pigmented lesion, showing a slightly lobulated surface with visible superficial vessels. b Histopathological examination of the lesion stained with hematoxylin eosin at $\times 100$ magnification, showing a cystic tubular lesion composed of tall, columnar, granular, eosinophilic cells. 